\title{
Predicted vitamin D status during pregnancy in relation to offspring forearm fractures in childhood: a study from the Danish National Birth Cohort
}

\author{
Sesilje B. Petersen ${ }^{1 *}$, Marin Strøm ${ }^{1}$, Ekaterina Maslova ${ }^{1}$, Charlotta Granström ${ }^{1}$, Peter Vestergaard ${ }^{2,3}$, \\ Christian Mølgaard ${ }^{4}$ and Sjurdur F. Olsen ${ }^{1,5}$ \\ ${ }^{1}$ Department of Epidemiology Research, Centre for Fetal Programming, Statens Serum Institut, DK-2300 \\ Copenhagen S, Denmark \\ ${ }^{2}$ Department of Endocrinology, Aalborg University Hospital, DK-9000 Aalborg, Denmark \\ ${ }^{3}$ Department of Clinical Medicine, Aalborg University, DK-9000 Aalborg, Denmark \\ ${ }^{4}$ Department of Nutrition, Exercise and Sports, Faculty of Science, University of Copenhagen, DK-1958 Frederiksberg C, \\ Denmark \\ ${ }^{5}$ Department of Nutrition, Harvard School of Public Health, Boston, MA 02115, USA \\ (Submitted 12 February 2015 - Final revision received 11 July 2015 - Accepted 18 August 2015 - First published online 2 October 2015)
}

\begin{abstract}
In a prospective cohort study, the association between maternal vitamin D status during pregnancy and offspring forearm fractures during childhood and adolescence was analysed in 30132 mother and child pairs recruited to the Danish National Birth Cohort between 1996 and 2002. Data on characteristics, dietary factors and lifestyle factors were collected on several occasions during pregnancy. We analysed the association between predicted vitamin D status, based on a subsample with 25-hydroxyvitamin D (25(OH)D) biomarker measurements ( $n$ 1497) from gestation week 25, and first-time forearm fractures among offspring between birth and end of follow-up. Diagnoses were extracted from the Danish National Patient Register. Multivariable Cox regression models using age as the underlying time scale indicated no overall association between predicted vitamin D status (based on smoking, season, dietary and supplementary vitamin D intake, tanning bed use and outdoor physical activity) in pregnancy and offspring forearm fractures. Likewise, measured 25(OH)D, tanning bed use and dietary vitamin D intake were not associated with offspring forearm fractures. In mid-pregnancy, $91 \%$ of the women reported intake of vitamin D from dietary supplements. Offspring of women who took $>10 \mu \mathrm{g} / \mathrm{d}$ in mid-pregnancy had a significantly increased risk for fractures compared with the reference level of zero intake (hazard ratios (HR) 1.31; $95 \%$ CI 1.06, 1.62), but this was solely among girls (HR 1.48; $95 \%$ CI $1 \cdot 10,2 \cdot 00)$. Supplement use in the peri-conceptional period exhibited similar pattern, although not statistically significant. In conclusion, our data indicated no protective effect of maternal vitamin D status with respect to offspring forearm fractures.
\end{abstract}

\section{Key words: Vitamin D: Fractures: Epidemiology: Pregnancy: Fetal programming}

Osteoporosis, characterised by the disruption of bone architecture and increased bone fracture risk, is a major public health issue and implies substantial costs to the society ${ }^{(1)}$. The disease may be prevented through increasing bone mass early in life to a degree that will have a biologically relevant effect in middle-aged and elderly people - for example, by the influence of diet, physical activity and endocrine status ${ }^{(2,3)}$. A growing body of evidence also suggests that adult bone mass may be influenced by factors operating as early as in fetal life ${ }^{(4)}$, and especially vitamin $\mathrm{D}$ status during pregnancy has been hypothesised to play a role ${ }^{(5-9)}$. It is well documented that vitamin $\mathrm{D}$ is a key factor in the regulation of $\mathrm{Ca}$ homoeostasis $^{(10)}$, and children born to women with low vitamin D status tend, apart from being lighter and smaller, to have lower bone mineral content at birth ${ }^{(11)}$. However, it is unclear whether maternal vitamin D status during pregnancy impacts offspring bone development as studies using measures from dual-energy X-ray absorptiometry (DXA) scans in childhood have shown conflicting results ${ }^{(5-9)}$.

Few studies have yet looked at the association between functional measures of bone health, such as bone fractures, in relation to prenatal vitamin D status. A meta-analysis from 2006 indicated an association between low bone mineral density (BMD) and bone fractures in children ${ }^{(12)}$, and a review from 2010 concluded that there is consistent and convincing evidence for an association between BMD and childhood risk of forearm fractures ${ }^{(13)}$. Forearm fractures seem to be a good indicator of low BMD compared with other types of fractures ${ }^{(13,14)}$, because they often occur as a consequence of falls on the same plane, and contrary to fractures caused by collisions or downhill falls, they do not require great forces to come into play.

Abbreviations: 25(OH)D, 25-hydroxyvitamin D; DNBC, Danish National Birth Cohort; HR, hazard ratio

* Corresponding author: S. B. Petersen, fax +45 32683868, email bondo@sesilje.dk 
In the large prospective Danish National Birth Cohort (DNBC), we had a unique opportunity to examine the association between predicted maternal vitamin $\mathrm{D}$ status and offspring forearm fractures through linkages to nationwide registries. Therefore, in the present study, we aimed at testing the hypothesis that a low maternal vitamin $\mathrm{D}$ status during pregnancy increases the risk of offspring forearm fractures during childhood and adolescence.

\section{Methods \\ Study population}

In the DNBC, a total of 101042 pregnancies were recruited between 1996 and 2002 during the first antenatal visit to the general practitioner at approximately 6-10 weeks of gestation. At recruitment, women provided consent for themselves and their unborn child for participation and later data linkage to Danish health registers ${ }^{(15)}$. During the recruitment period, approximately $35 \%$ of all deliveries in Denmark (predominantly only Caucasian mothers) were included in the cohort $^{(15)}$. The initial data collection consisted of an enrolment form covering personal information as well as medication and dietary supplement use. The pregnant women were interviewed four times by telephone about lifestyle and diseases; two prenatal interviews were conducted during gestational weeks 12 and 30 and two postnatal interviews were conducted when the child was 6- and 18-months old. In addition, a validated semi-quantitative FFQ was mailed to the women during gestation week 25 , covering the diet during the previous 4 weeks of completion ${ }^{(15,16)}$. The DNBC was conducted according to the guidelines laid down in the Declaration of Helsinki, and all the procedures involving study participants were approved by the National Committee on Health Research Ethics. Further, the study is registered by the Danish Data Protection Agency (J.nr. 2009-41-3332).

\section{Exposure assessment}

Vitamin $D$ prediction scores. A vitamin $\mathrm{D}$ prediction score model was created based on biomarker assessment of 25-hydroxyvitamin $\mathrm{D}_{2} \quad\left(25(\mathrm{OH}) \mathrm{D}_{2}\right)$ and $\mathrm{D}_{3} \quad\left(25(\mathrm{OH}) \mathrm{D}_{3}\right)$ concentrations in 1497 maternal blood samples collected by the general practitioner at 25 weeks of gestation ${ }^{(17)}$. The samples were part of a previous case-control study of postpartum depression (893 non-cases and 605 cases), which showed no overall association between maternal status of vitamin D and the risk of postpartum depression ${ }^{(18)}$. Concentrations of plasma $25(\mathrm{OH}) \mathrm{D}_{2}$ and $25(\mathrm{OH}) \mathrm{D}_{3}$ were measured by the liquid chromatography-tandem MS method with a vitamin D kit from PerkinElmer, which is considered to be an accurate measure of vitamin D status ${ }^{(19)}$. The vitamin D prediction score was constructed by including factors previously associated with vitamin D status and examining their ability to predict measured vitamin D status in a regression model. The final prediction score included smoking, season, dietary and supplementary vitamin $\mathrm{D}$ intake, tanning bed use and outdoor physical activity level ( $n$ 36977). Validation of the model in an independent sample with vitamin D measurements showed good ability to rank individuals according to vitamin $\mathrm{D}$ status. The model explained $40 \%$ of the variation in total 25 -hydroxyvitamin D $25(\mathrm{OH}) \mathrm{D}$ levels, and it reflected fair agreement between measured concentrations of total $25(\mathrm{OH}) \mathrm{D}$ and predicted vitamin $\mathrm{D}$ status $^{(17)}$.

Dietary vitamin D. Information about dietary intake of vitamin D was available from the FFQ in mid-pregnancy with questions on frequencies of intake of approximately 360 different items of foods and beverages ${ }^{(16)}$. To estimate the intake of vitamin D, standard portion sizes and standard recipes were applied for all items in the questionnaire. Standard portion sizes were multiplied with the daily frequencies to estimate intake of each food item in grams and then coupled with the Danish Food Tables to estimate the daily intake of vitamin $\mathrm{D}^{(20)}$. Intake of vitamin $\mathrm{D}$ was energy-adjusted by the residual method described by Willett et al. ${ }^{(21)}$. The FFQ has been validated in a group of younger non-pregnant women ${ }^{(22)}$, and also in a subsample from the DNBC for the intake of fruits, vegetables and pregnancy-relevant nutrients (folate, protein, retinol and $n-3$ fatty acids) by a 7-d weighed food diary and by biomarkers $^{(23,24)}$

Supplementary vitamin D. Data on dietary supplements were available from the enrolment form and from the FFQ. Intake of vitamin $\mathrm{D}$ in the peri-conceptional period, defined as estimated daily intakes in weeks $0-8$ of gestation, was extracted from the enrolment form, where women reported the name, manufacturer, period and dose of each supplement used since 4 weeks before the 1 st day of the last menstruation period (LMP) until the day of enrolment (maximum 14 weeks after LMP). Intake of vitamin D during mid-pregnancy was extracted from the FFQ, where women wrote the name, manufacturer and dose of each supplement. To estimate daily vitamin D intake, information from the enrolment form and the FFQ, respectively, was linked to nutritional ingredient data for supplements sold in Denmark during the study period. Data were gathered from the Danish Medicines Agency and the Danish Veterinary and Food Administration.

Tanning bed use. We extracted data on tanning bed use in pregnancy from the telephone interview at 30 weeks of gestation, where the women answered a question about using tanning beds and during which gestational weeks they used them. Answers for gestational weeks 1-25 were summarised and divided into four exposure groups according to the number of weeks they used tanning beds (no use, 1-4, 4-8, >8 weeks). Further, the answers were summarised for the first trimester (gestation weeks 1-12) and the second trimester (gestation weeks 12-25), respectively.

\section{Outcome}

For our outcome, we extracted data from the Danish National Patient Register (DNPR) by means of the unique Danish personal identifier (CPR). The DNPR is a mandatory nationwide register established in 1977, recording information from all hospital admissions, including outpatient activities and 
emergency room contacts $^{(25)}$. In general, the register has a high precision of diagnoses ${ }^{(26)}$, and also for fracture diagnoses ${ }^{(27)}$. Fracture diagnoses are registered along with cause of diagnosis, including data on involvement in a traffic accident. We defined our outcome as the first occurrence of any forearm fracture between birth and end of follow-up using the ICD-10 codes. The following codes for forearm fractures were used in the study: DS525, DS526, DS525A, DS525B and DS525C. For other fracture diagnoses, we used the following codes: DS020DS029, DS120-DS129，DS220-DS229，DS302P，DS320-DS329, DS420-DS429, DS520-DS529, DS620-DS629, DS720-DS729, DS820-DS829, DS920-DS929 and DT020-DT029.

\section{Statistical methods}

The study sample for our analyses consisted of 30132 mother-child pairs who had available information on predicted vitamin $\mathrm{D}$ status, except for the analysis on peri-conceptional use of vitamin D that consisted of 18635 mother-child pairs with completed information on the use of dietary supplements in the enrolment form (Fig. 1). We analysed the association between different measures of vitamin D status in pregnancy and offspring forearm fractures using Cox proportional hazard models and calculated hazard ratios (HR) and 95\% CI, using age in days as the underlying time scale. Kaplan-Meier estimates were used to visualise the associations. We restricted our study sample to live births, singletons and offspring with a validated CPR number. All exposure measures were analysed both as continuous and categorical variables as follows: vitamin $\mathrm{D}$ prediction scores (quintiles), dietary vitamin $\mathrm{D}$ intake (quintiles), total 25(OH)D concentration $(<25,25$ to $<50,50-75$ and $>75 \mathrm{nmol} / \mathrm{l}$, according to guidelines from the Danish National Board of Health and the American Institute of Medicine $\left.{ }^{(28,29)}\right)$, peri-conceptional supplementary vitamin D intake $(0,0-5,>5-10 \mu \mathrm{g} / \mathrm{d})$ and mid-pregnancy supplementary vitamin $D$ intake $(0,0-5,5-10$ and $>10 \mu \mathrm{g} / \mathrm{d})$. Season of birth

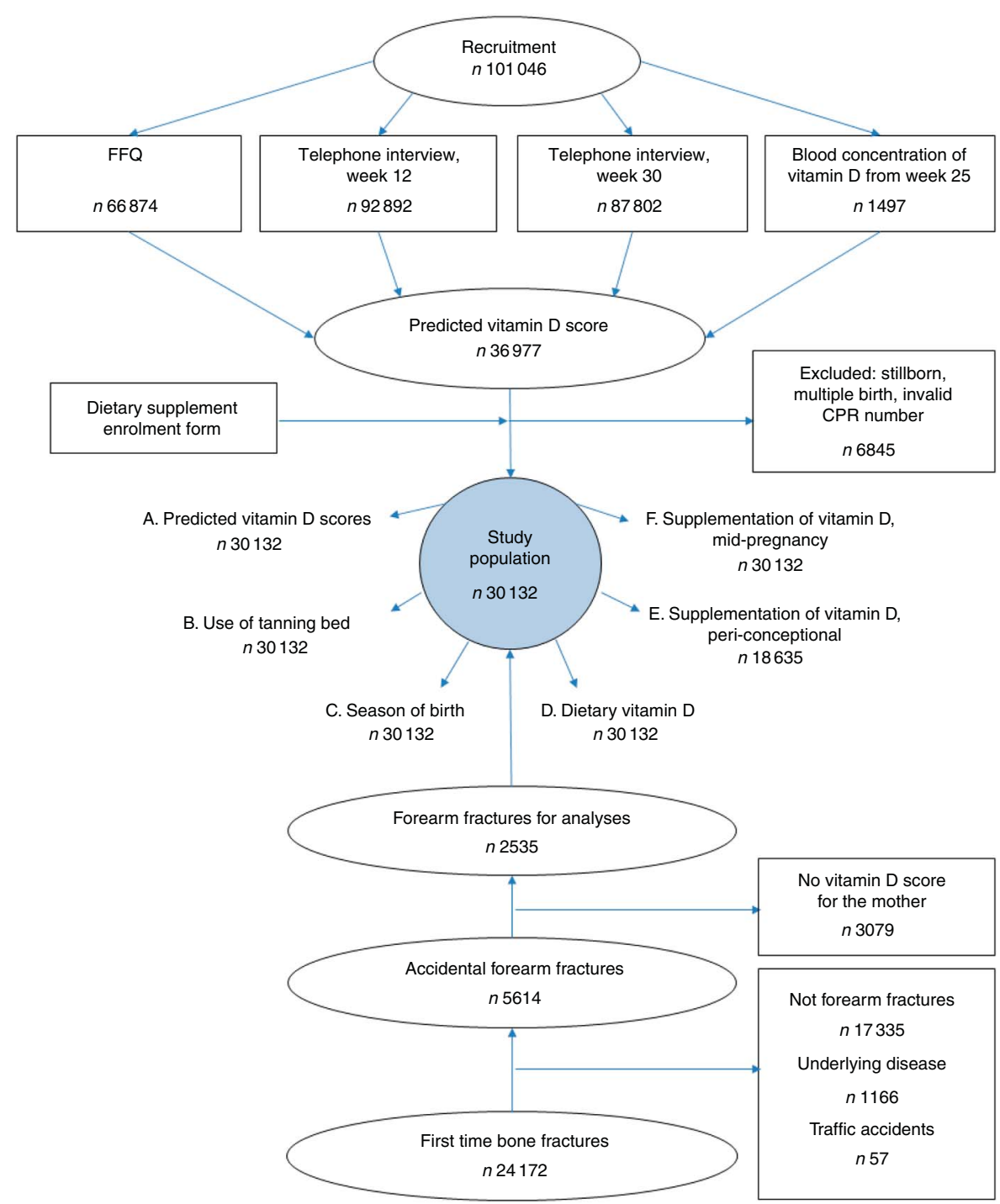

Fig. 1. Flow chart of the data collection in the Danish National Birth Cohort, and elucidation of the analyses conducted for the association between maternal vitamin $D$ status during pregnancy and offspring forearm fracture risk. CPR, Danish personal identifier. 
was analysed as a categorical variable (Mar/Apr/May, Jun/Jul/ Aug, Sep/Oct/Nov and Dec/Jan/Feb). Visual inspection of cumulative residual plots did not indicate violations to the assumption of proportional hazards.

Children in the study sample were followed-up from their date of birth until the age of first forearm fracture, other censoring event or the defined end of follow-up, which was 10 November 2013. In total, 1891 children (2\%) in the study sample were censored due to other reasons, including death or emigration, according to data from the Danish Civil Registration System.

Information on covariates used in the multivariable Cox regression analyses was gathered from the enrolment form, the FFQ and the prenatal telephone interviews. Based on accessibility and previous evidence about vitamin $\mathrm{D}$ and fracture risk, the following variables were included as covariates: mother's age (continuous), parity $(0,1,2,3+)$, sex of the child (boy/girl), cohabitation (couple/single), pre-pregnancy BMI (continuous), smoking (non-smoker, occasional smoker, $<15,>15$ cigarettes/d), occupational status (high, medium, skilled, student, unskilled, unemployed) and physical activity (0, 1-44, 45-75, 75-149, $\geq 150 \mathrm{~min} /$ week). We adjusted for season of birth in all analyses, except for those in which season of birth was the exposure. In the vitamin D score analysis, we did not adjust for smoking, season and physical activity, because the variables were components of the prediction score model.

The proportion of missing values varied from $0.05 \%$ (maternal age) to $1.8 \%$ (pre-pregnancy BMI), and we substituted missing values by the median/mode for the variable in question. All the analyses were carried out using SAS statistical software (version 9.4; SAS Institute). In sensitivity analyses, we adjusted for offspring birth weight and gestational age as continuous variables. When we analysed the association between mid-pregnancy supplementary intake of vitamin $\mathrm{D}$, we adjusted for the supplementary intake of $\mathrm{Ca}$ as a continuous variable in the sensitivity analysis

\section{Results}

In total, 24172 children from the DNBC were registered with at least one bone fracture in the DNPR. Of the fractures caused by accidents ( $86 \%$ ), the main locations of fracture were the elbow and forearm ( $41 \%$ ), and the remaining fractures were in the hand, wrist or fingers (18\%), shoulder or upper arm (17\%), lower leg or ankle (9\%), feet or toes (10\%), skull or face (4\%), thigh and hip ( $1 \%$ ) or other areas of the body (0.3\%). In total, 5614 first-time forearm fractures were recorded when we restricted to forearm fractures from accidents and excluded fractures from traffic accidents. This provided us with 2216 forearm fractures for the analyses in the final study sample of 30132 mother-child pairs (30\% of the population) with a predicted vitamin D score from the pregnancy (Fig. 1). Mean fracture age among the children was 7.9 (SD 3.2) years (range $0 \cdot 5-14 \cdot 1$ ). Background characteristics of the study population are shown in Table 1 , along with the distribution of pregnant women according to characteristics and
Table 1. Background characteristics of participants in the Danish National Birth Cohort according to offspring forearm fractures ( $n 30$ 132)

\begin{tabular}{|c|c|c|c|}
\hline & \multicolumn{2}{|c|}{ Forearm fractures } & \multirow[b]{2}{*}{$P^{*}$} \\
\hline & Yes & No & \\
\hline Maternal age (mean, years) & 30.5 & 30.4 & 0.77 \\
\hline Pre-pregnancy BMI (mean, kg/m²) & $23 \cdot 8$ & 23.6 & 0.004 \\
\hline Cohabitation status (\%) & & & 0.41 \\
\hline Couple & $98 \cdot 7$ & 98.5 & \\
\hline Single & 1.3 & 1.5 & \\
\hline Occupational status (\%) & & & 0.23 \\
\hline High & $24 \cdot 1$ & 23.5 & \\
\hline Medium & $31 \cdot 1$ & $32 \cdot 3$ & \\
\hline Skilled & $28 \cdot 7$ & $27 \cdot 1$ & \\
\hline Student & $5 \cdot 0$ & $5 \cdot 4$ & \\
\hline Unskilled & $9 \cdot 3$ & $10 \cdot 3$ & \\
\hline Unemployed & 1.7 & 1.4 & \\
\hline Physical activity (min/week) & & & 0.061 \\
\hline 0 & $51 \cdot 0$ & $50 \cdot 8$ & \\
\hline $1-44$ & $17 \cdot 0$ & $16 \cdot 6$ & \\
\hline $45-75$ & 11.9 & $12 \cdot 0$ & \\
\hline $75-149$ & 11.3 & $13 \cdot 0$ & \\
\hline$\geq 150$ & 8.8 & 7.6 & \\
\hline Maternal smoking (\%) & & & 0.81 \\
\hline Non-smoker & $77 \cdot 3$ & $76 \cdot 6$ & \\
\hline Occasional smoker (cigarettes/d) & $12 \cdot 0$ & $12 \cdot 4$ & \\
\hline$<15$ & $9 \cdot 0$ & $9 \cdot 4$ & \\
\hline$>15$ & 1.7 & 1.6 & \\
\hline Parity (\%) & & & $<0.001$ \\
\hline 0 & 46.5 & $50 \cdot 3$ & \\
\hline 1 & $39 \cdot 0$ & $35 \cdot 1$ & \\
\hline 2 & $12 \cdot 3$ & $12 \cdot 0$ & \\
\hline $3+$ & $2 \cdot 2$ & $2 \cdot 6$ & \\
\hline Child sex (\%) & & & 0.92 \\
\hline Boy & $50 \cdot 4$ & 50.5 & \\
\hline Girl & $49 \cdot 6$ & 49.5 & \\
\hline Gestational age (mean, weeks) & 280.7 & 280.5 & 0.52 \\
\hline Birth weight (mean, g) & 3627 & 3593 & 0.005 \\
\hline
\end{tabular}

* Overall $x^{2}$ test of effect.

offspring forearm fractures. Women whose offspring experienced forearm fractures were found to be of higher parity, have higher pre-pregnancy BMI and offspring with higher birth weight.

Estimated vitamin D status by prediction scores was not associated with offspring risk of forearm fractures in our data (Table 2), and adjustment for potential confounders did not change this result, just as stratification by sex did not indicate significant differences between boys and girls. When we used the measured vitamin D status in the restricted sample of women with available biomarker measurements, we observed similar results: $25(\mathrm{OH}) \mathrm{D}$ concentration was not associated with offspring forearm fractures. Further adjustment for gestational age and birth weight in sensitivity analyses did not change these results (data not shown).

Tanning bed use in pregnancy was reported by $18.3 \%$ of the study population, and $7.8 \%$ used tanning beds in both the first and the second trimester. No associations were found between the use of tanning beds and offspring risk for forearm fractures (Table 2). The results were unchanged when we analysed the use during the first and second trimester separately and when we stratified by season (data not shown). With regard to season of birth, there was a borderline significant increased risk of 
Table 2. Hazard ratios (HR) of offspring forearm fractures in Danish National Birth Cohort according to different sources of vitamin D during pregnancy (Hazard ratios and $95 \%$ confidence intervals; mean values and standard deviations)

\begin{tabular}{|c|c|c|c|c|c|c|c|c|c|c|}
\hline & \multirow[b]{2}{*}{$n$} & \multirow[b]{2}{*}{ Cases } & \multicolumn{2}{|r|}{ Crude } & \multicolumn{2}{|c|}{ Adjusted } & \multicolumn{2}{|r|}{ Boys } & \multicolumn{2}{|r|}{ Girls } \\
\hline & & & $\mathrm{HR}$ & $95 \% \mathrm{Cl}$ & $\mathrm{HR}^{*}$ & $95 \% \mathrm{Cl}$ & $\mathrm{HR}^{*}$ & $95 \% \mathrm{Cl}$ & $H R^{*}$ & $95 \% \mathrm{Cl}$ \\
\hline \multicolumn{11}{|c|}{ Vitamin D scores $(\mu \mathrm{g} / \mathrm{d})$} \\
\hline Q1 (39.1 (sD 31.2)) & 6030 & 435 & 1.00 & & 1.00 & & 1.00 & & 1.00 & \\
\hline Q2 (51.1 (SD 2.2)) & 5990 & 444 & 1.03 & $0.90,1.17$ & 1.03 & $0.91,1.18$ & $1 \cdot 10$ & $0.91,1.32$ & 0.97 & $0.80,1.17$ \\
\hline Q3 (58.6 (SD 2.2)) & 6064 & 469 & 1.07 & $0.94,1.22$ & 1.08 & $0.95,1.23$ & 1.13 & $0.94,1.36$ & 1.03 & $0.86,1.24$ \\
\hline Q4 (66.7 (SD 2.7)) & 6036 & 415 & 0.96 & $0.84,1 \cdot 10$ & 0.97 & $0.85,1.12$ & 1.07 & $0.88,1.29$ & 0.88 & $0.73,1.07$ \\
\hline Q5 (81.3 (SD 8.2)) & 6012 & 453 & 1.07 & $0.94,1.22$ & 1.09 & $0.96,1.25$ & 1.03 & $0.85,1.25$ & 1.15 & $0.96,1.38$ \\
\hline$P$ (class) $\dagger$ & & & & 0.42 & & 0.35 & & 0.70 & & 0.090 \\
\hline$P$ (cont) $\ddagger$ & & & & 0.28 & & 0.15 & & 0.47 & & 0.21 \\
\hline \multicolumn{11}{|l|}{ Tanning bed use } \\
\hline No use & 24602 & 1798 & 1.00 & & 1.00 & & 1.00 & & 1.00 & \\
\hline$<4$ weeks & 2852 & 223 & 1.08 & $0.94,1.24$ & $1 \cdot 10$ & $0.96,1.27$ & 1.05 & $0.86,1.28$ & 1.17 & $0.96,1.42$ \\
\hline 4-12 weeks & 1556 & 120 & 1.06 & $0.88,1.27$ & 1.08 & $0.89,1.29$ & 0.99 & $0.76,1.30$ & 1.15 & $0.89,1.49$ \\
\hline$>12$ weeks & 1122 & 75 & 0.91 & $0.73,1.15$ & 0.93 & $0.74,1.18$ & 0.84 & $0.59,1.19$ & 1.02 & $0.75,1.40$ \\
\hline$P$ (class) $\dagger$ & & & & 0.56 & & 0.42 & & 0.73 & & 0.35 \\
\hline$P$ (cont) $\ddagger$ & & & & 0.36 & & 0.46 & & 0.35 & & 0.90 \\
\hline \multicolumn{11}{|l|}{ Season of birth } \\
\hline Dec/Jan/Feb & 7088 & 511 & 1.04 & $0.92,1.17$ & 1.04 & $0.92,1 \cdot 18$ & 1.00 & $0.84,1.19$ & 1.08 & $0.91,1.29$ \\
\hline Mar/Apr/May & 7056 & 492 & 1.00 & & 1.00 & & 1.00 & & 1.00 & \\
\hline Jun/Jul/Aug & 7887 & 624 & $1 \cdot 12$ & $0.99,1.26$ & $1 \cdot 12$ & $1.00,1.26$ & $1 \cdot 17$ & $0.99,1.39$ & 1.07 & $0.90,1.27$ \\
\hline Sep/Oct/Nov & 8101 & 589 & 1.03 & $0.92,1.17$ & 1.04 & $0.92,1.17$ & $1 \cdot 10$ & $0.93,1.31$ & 0.98 & $0.82,1.16$ \\
\hline$P$ (class) $\dagger$ & & & & 0.28 & & 0.27 & & 0.15 & & 0.54 \\
\hline \multicolumn{11}{|c|}{ Dietary vitamin $D(\mu \mathrm{g} / \mathrm{d})$} \\
\hline Q1 (1.6 (SD 0.6)) & 5986 & 422 & 1.00 & & 1.00 & & 1.00 & & 1.00 & \\
\hline Q2 (2.1 (SD 0.1)) & 6132 & 440 & 1.01 & $0.88,1.15$ & 1.00 & $0.88,1.15$ & 1.23 & $1.02,1.49$ & 0.82 & $0.68,0.99$ \\
\hline Q3 (2.7 (SD 0.2)) & 5894 & 434 & 1.02 & $0.89,1.17$ & 1.02 & $0.89,1.17$ & $1 \cdot 17$ & $0.96,1.42$ & 0.89 & $0.75,1.08$ \\
\hline Q4 (3.6 (sD 0.3)) & 6064 & 474 & $1 \cdot 10$ & $0.96,1.25$ & $1 \cdot 10$ & $0.97,1.26$ & 1.30 & $1.08,1.58$ & 0.94 & $0.78,1.13$ \\
\hline Q5 (6.1 (SD 2.2)) & 5945 & 439 & 1.05 & $0.91,1.19$ & 1.06 & $0.92,1.21$ & $1 \cdot 13$ & $0.93,1.38$ & 1.00 & $0.83,1.21$ \\
\hline$P$ (class) $\dagger$ & & & & 0.62 & & 0.54 & & 0.078 & & 0.39 \\
\hline$P$ (cont) $\ddagger$ & & & & 0.39 & & 0.28 & & 0.53 & & 0.37 \\
\hline \multicolumn{11}{|c|}{$\begin{array}{l}\text { Supplementation of vitamin } D \text {, } \\
\text { peri-conceptional }(\mu \mathrm{g} / \mathrm{d})\end{array}$} \\
\hline 0 & 1685 & 102 & 1.00 & & 1.00 & & 1.00 & & 1.00 & \\
\hline $0-5$ & 11654 & 852 & $1 \cdot 21$ & $0.98,1.48$ & $1 \cdot 20$ & $0.98,1.48$ & 1.21 & $0.90,1.63$ & 1.20 & $0.90,1.60$ \\
\hline$>5$ & 5296 & 392 & 1.23 & $0.99,1.54$ & 1.23 & $0.99,1.53$ & $1 \cdot 16$ & $0.84,1.59$ & 1.30 & $0.96,1.77$ \\
\hline$P$ (class) $\dagger$ & & & & 0.15 & & 0.17 & & 0.43 & & 0.21 \\
\hline$P$ (cont) $\ddagger$ & & & & 0.19 & & 0.22 & & 0.51 & & 0.30 \\
\hline \multicolumn{11}{|c|}{$\begin{array}{l}\text { Supplementation of vitamin } D \text {, } \\
\text { mid-pregnancy }(\mu \mathrm{g} / \mathrm{d})\end{array}$} \\
\hline 0 & 2576 & 173 & 1.00 & & 1.00 & & 1.00 & & 1.00 & \\
\hline$>0-5$ & 10159 & 737 & 1.08 & $0.91,1.27$ & 1.08 & $0.91,1.28$ & 1.09 & $0.87,1.37$ & 1.08 & $0.84,1.37$ \\
\hline$>5-10$ & 13478 & 988 & $1 \cdot 10$ & $0.94,1.29$ & $1 \cdot 11$ & $0.95,1.31$ & 1.02 & $0.81,1.27$ & 1.22 & $0.96,1.54$ \\
\hline$>10$ & 2028 & 172 & 1.30 & $1.05,1.60$ & 1.31 & $1.06,1.62$ & $1 \cdot 16$ & $0.86,1.56$ & 1.48 & $1.10,2.00$ \\
\hline$P$ (class) $\dagger$ & & & & 0.086 & & 0.071 & & 0.59 & & 0.17 \\
\hline$P$ (cont) $\ddagger$ & & & & 0.029 & & 0.019 & & 0.45 & & 0.013 \\
\hline
\end{tabular}

Q, quintile.

* Adjusted for maternal age, parity, sex of the child, cohabitation, pre-pregnancy BMI, smoking, occupational status, season and physical activity. (Analyses on vitamin D scores are not adjusted for smoking, season and physical activity; analyses on season of birth are not adjusted for season; boys and girls, respectively, are not adjusted for sex of the child.)

$\dagger$ Overall $X^{2}$ test of effect.

$\ddagger$ Continuous values of vitamin $D$ status in the Cox regression model.

forearm fractures for offspring born in Jun/Jul/Aug $v$. Mar/Apr/ May. However, stratification by sex revealed that the association was present only for boys (Table 2).

Dietary intake of vitamin D in mid-pregnancy was not associated with the risk of offspring forearm fractures (Table 2). However, stratification by sex indicated that boys in the second and fourth quintile had a significantly higher HR compared with boys in the first quintile, although when data were analysed as continuous no significant association was found $(P=0.53)$. According to our data, the dietary intake of vitamin $D$ during pregnancy was relatively low (median 2.66 ( 5 th-95th percentile $1.43-6.67) \mu \mathrm{g} / \mathrm{d})$.
Data on supplement use in the peri-conceptional period was available for $62 \%$ of the study population, of whom $91 \%$ took at least one dietary supplement with vitamin $\mathrm{D}$, which provided a median of 5.0 (5th-95th percentile $1.25-10.00) \mu \mathrm{g} / \mathrm{d}$ of vitamin D. In both the crude $(P=0.057)$ and the adjusted analysis $(P=0.063)$, there was a borderline significant association between intakes $>5.0 \mu \mathrm{g} / \mathrm{d} v$. zero intake and the risk of offspring forearm fractures (Table 2), so that supplementation with vitamin $\mathrm{D}$ in the peri-conceptional period increased the risk for fractures. Stratification by sex did not indicate sex-specific effects, but daughters of women with an intake above $5.0 \mu \mathrm{g} / \mathrm{d}$ had a tendency for increased risk of fractures 
$(P=0.084)$. However, when analysed as a continuous variable, there was no significant association between supplemental vitamin $\mathrm{D}$ intake in the peri-conceptional period and fracture risk.

In mid-pregnancy, $91 \%$ of women with dietary supplement information available took one or more dietary supplements with vitamin $\mathrm{D}$, which provided a daily median intake of 10 (5th-95th percentile $4.46-15.00) \mu \mathrm{g} / \mathrm{d}$ among supplement users. Mid-pregnancy supplemental vitamin D intake was significantly associated with the risk of offspring forearm fractures (Table 2). Offspring of women who took $>10 \mu \mathrm{g}$ of vitamin $\mathrm{D} / \mathrm{d}$ had a significant higher risk of forearm fractures compared with the reference level of zero intake (HR 1.31; $95 \%$ CI $1.06,1.62)$. Stratifying by sex revealed that the significant association was present only for girls (HR 1.48; $95 \%$ CI $1 \cdot 10,2 \cdot 00$ ), whereas no significant association was found for boys (HR 1.16; $95 \%$ CI 0.86, 1.56). When we further adjusted for intake of $\mathrm{Ca}$ from dietary supplements, the risk estimate increased for girls (HR 1.67; $95 \%$ CI 1.20, 2.32), which indicated that the association was independent of the supplementary intake of $\mathrm{Ca}$. When we stratified for season in the analysis, we found that the higher risk of forearm fractures was present only in girls born during winter (HR 2.06; $95 \%$ CI 1.14, 3.74), whereas no association was found for girls born during summer (HR 1.15; $95 \%$ CI 0.67, 1.96). For boys, no significant associations where found between zero intake and a supplemental intake $>10 \mu \mathrm{g}$ of vitamin $\mathrm{D} / \mathrm{d}$, both during summer (HR 1.04; $95 \%$ CI 0.61, 1.79) and winter (HR 1.18; $95 \%$ CI $0 \cdot 58,2 \cdot 40)$.

\section{Discussion}

Overall, there was no association between maternal vitamin D status and offspring risk of forearm fractures during childhood in the DNBC. In the supplementary analyses, we analysed the role of vitamin D sources from the prediction score model, but again we found no indication of a protective effect of vitamin D-related exposures on offspring forearm fracture risk; neither maternal use of tanning bed nor dietary or supplementary intake of vitamin D decreased the risk of offspring forearm fractures. However, contrary to our hypothesis, we found a positive association between maternal vitamin D supplementation and offspring forearm fracture risk.

\section{Strengths and limitations}

The strengths of the present study include the large study sample and the availability of data on several maternal sources of vitamin D. In our study, we examined both the overall predicted status of vitamin $\mathrm{D}$, use of a tanning bed and intake from diet and dietary supplements. Furthermore, for our outcome measure, we used data on fractures with high validity $^{(26,27)}$. A major limitation of the study is the lack of information about offspring weight and height, which may be related both to maternal vitamin D status and to offspring bone mass. Likewise, we do not have information about offspring vitamin D status, physical activity level, sunlight exposure or diet during childhood, thus our results may be confounded when those data are missing.

We cannot preclude misclassification of vitamin D status in our analyses, as we used predicted levels of vitamin D status and not measured levels of $25(\mathrm{OH}) \mathrm{D}$. However, a study examining only the association with $25(\mathrm{OH}) \mathrm{D}$ would for one be very costly and second would use highly valuable and limited biomaterial, making it an unrealistic goal. The predicted status of vitamin D allows us to conduct a study with the present purpose on a large study sample, and still maintain a high data quality. In an exposure-disease approach using predicted vitamin D scores instead of biomarker measurements, we must expect random measurement error to attenuate the measure of association; however, the potential loss in precision may be recovered by the larger study sample available when using predicted vitamin D status ${ }^{(30)}$. Other studies defining prediction models of vitamin D status showed 25(OH)D concentrations to be predicted quite accurately by a range of demographic and lifestyle factors ${ }^{(30-33)}$. Several studies have been published using predicted vitamin D scores when testing exposuredisease hypotheses ${ }^{(30,34-37)}$, and the method seems to be broadly accepted for an epidemiological approach in large cohort studies. In general, the experiences all indicate that, although the prediction scores are not appropriate for use on an individual level, they are suitable for ranking groups with respect to high- and low-exposure categories ${ }^{(30)}$. On this basis, the prediction scores in the present study were analysed as quintiles and not as defined status groups according to guidelines from health agencies.

\section{Possible confounding in relation to vitamin $D$ supplementation}

Contrary to our hypothesis, we found that supplement intake of vitamin D in mid-pregnancy was associated with higher forearm fracture risk, but stratification by sex and season revealed that the increased risk was only present for girls born during winter. The analysis on supplement intake of vitamin D from the peri-conceptional period indicated a similar pattern: girls had a borderline increased risk for fractures if the mother took $>5 \mu \mathrm{g} / \mathrm{d}$ of vitamin $\mathrm{D}$ in the peri-conceptional period; however, there was no linear trend. Information on supplement use in the peri-conceptional period was not available for the entire study sample. The highest intake during the peri-conceptional period was only $>5 \mu \mathrm{g} / \mathrm{d}$, whereas it was $>10 \mu \mathrm{g} / \mathrm{d}$ in mid-pregnancy, and this discrepancy may have affected our results. Almost all women who reported taking a dietary supplement took mixed supplements with other nutrients, such as multivitamins. During the recruitment period, dietary supplements sold on the Danish market and intended for pregnant women mostly contained 5 or $10 \mu \mathrm{g}$ of vitamin D. If a woman took $>10 \mu \mathrm{g} / \mathrm{d}$ of vitamin D, we believe it to be a reflection of her having doubled or tripled the recommended dose, meaning that she was likely to have also increased her dose of other vitamins and minerals to very high intake levels. Therefore, our results may reflect the effect of other nutrients - for example, vitamin A - which seems to be associated with increased risk of bone fractures in adults, although the results are conflicting ${ }^{(38)}$. 
In sensitivity analyses, we adjusted for mid-pregnancy intake of $\mathrm{Ca}$ from dietary supplements, which if anything tended to strengthen an association for vitamin $\mathrm{D}$ intake, indicating that our finding of a direct association between supplemental intake of vitamin D in mid-pregnancy and risk of offspring forearm fractures was not caused or biased by the intake of $\mathrm{Ca}$. Review of the literature has concluded that there are no effects of vitamin D supplementation on bone fracture risk among adults, when the vitamin is taken as a single vitamin without $\mathrm{Ca}^{(39)}$. A double-blinded placebo-controlled trial on older women aged $70+$ years actually showed an increased risk of falls and fractures when women received each year, for $3-5$ years (in autumn or winter), an annual high dose (12.5 $\mathrm{mg}$ ) of oral vitamin $\mathrm{D}$ as a single vitamin without $\mathrm{Ca}^{(40)}$. The results are not comparable with our results in young people, but they indicate that there might be mechanisms and effects of vitamin D supplementation, which still need to be examined. Randomised controlled trials (RCT) on vitamin D supplementation alone are limited, and especially in pregnancy. Further studies are required to evaluate the role of vitamin D supplementation on fetal and offspring health ${ }^{(41)}$.

Our finding of a direct association between maternal supplemental vitamin D in mid-pregnancy and offspring bone fractures may be confounded by the underlying differences between women who reported high doses of dietary supplements $v$. women who did not report use of dietary supplements during pregnancy. A previous study from the DNBC ( $n$ 68 447) showed that women taking low $v$. high doses were different with respect to several characteristics ${ }^{(42)}$. Women with the highest dietary intake of vitamin $\mathrm{D}$ were also those with the highest supplementary intake. The determinants for a sufficient intake ( $\geq 10 \mu \mathrm{g} / \mathrm{d})$ were high maternal age, nulliparity and nonsmoking, all variables that we adjusted for in our analyses.

\section{Hypotheses for a negative effect of vitamin $D$ supplementation during pregnancy}

At Northern latitudes, everyday life during summer is quite different from that of winter, because of major changes in weather and sunlight exposure. The seasonal variation seems for instance to influence the levels of both melatonin, vitamin $\mathrm{D}$, serotonin and cortisol in humans ${ }^{(43-47)}$. It has been suggested that supplementation with vitamin D can bring a 'message of light' to the pineal gland and consequently decrease melatonin synthesis during night ${ }^{(48)}$. Melatonin crosses the placenta freely without being altered ${ }^{(49)}$, and we can therefore speculate that supplementation with vitamin D during sun-deprived periods may disturb melatonin synthesis. It has been hypothesised that interactions between melatonin, vitamin $\mathrm{D}$, serotonin and cortisol during pregnancy may be important in early offspring developmental aetiology of different diseases via their effect on many organs and tissues ${ }^{(50)}$. Schizophrenia and autoimmune diseases have been the main foci of this hypothesis, but it is likely that melatonin, vitamin $\mathrm{D}$ and serotonin also effect offspring bone heath, as they appear to influence skeletal bones in adults ${ }^{(51-54)}$.

Interestingly, a recently published RCT including 446 postmenopausal women found that vitamin D supplementation $(27.5 \mu \mathrm{g} / \mathrm{d})$ for at least 12 months changed the DNA methylation of some of the CYP family genes ${ }^{(55)}$. The $25(\mathrm{OH}) \mathrm{D}-1 \alpha$ hydroxylase enzyme (CYP27B1), responsible for conversion of $25(\mathrm{OH}) \mathrm{D}$ to 1,25 -dihydroxyvitamin $\mathrm{D}\left(1,25(\mathrm{OH})_{2} \mathrm{D}\right)$, the active form of the vitamin, was not part of the examined genes; however, if the gene can also be regulated by vitamin D supplementation during pregnancy, this may influence the fetal level of $1 \cdot 25(\mathrm{OH})_{2} \mathrm{D}$, as $1,25(\mathrm{OH})_{2} \mathrm{D}$ does not cross the placenta. Only $25(\mathrm{OH}) \mathrm{D}$ crosses the placenta and is converted to $1.25(\mathrm{OH})_{2} \mathrm{D}$ in the kidneys of the fetus. In the concept of fetal programming, expression of genes during pregnancy may be affected by the influence of dietary and environmental factors, with lasting effects on human health ${ }^{(56,57)}$. We can speculate that CYP27B1 may be down-regulated during pregnancy to suppress high levels of $1,25(\mathrm{OH})_{2} \mathrm{D}$ if the $25(\mathrm{OH}) \mathrm{D}$ status is highly elevated as a consequence of vitamin D supplementation. If this hypothesis is true, the expression of CYP27B1 in the offspring later during childhood may be down-regulated, and lead to lower bone mass accrual as a consequence of low $1 \cdot 25(\mathrm{OH})_{2} \mathrm{D}$ levels. This somewhat speculative hypothesis could explain a direct association between vitamin D supplementation during pregnancy and offspring bone fractures.

\section{Concluding remarks}

In conclusion, our study showed no association between predicted maternal status of vitamin D in mid-pregnancy and offspring forearm fracture risk. However, contrary to our hypothesis, dietary supplement use during mid-pregnancy, with a vitamin D dose $>10 \mu \mathrm{g} / \mathrm{d} v$. zero intake, was associated with increased forearm fracture risk in offspring, and especially among girls. Further investigation into this field is highly needed to clarify whether dietary supplements with vitamin D during pregnancy may have a non-beneficial impact on offspring bone development and health.

\section{Acknowledgements}

The authors would like to acknowledge all who have contributed to the present study, including laboratory staff, people who have worked or are still working on the Danish National Birth Cohort, and colleagues at Statens Serum Institut.

This study was supported by the Danish Council for Strategic Research (09-067124). The Danish National Birth Cohort has been financed by the March of Dimes Birth Defects Foundation, the Danish Heart Association, the Danish Medical Research Council and the Sygekassernes Helsefond, Danish National Research Foundation, Danish Pharmaceutical Association, Ministry of Health, National Board of Health and Statens Serum Institut. None of the listed sources of funding had any role in the design, analysis or writing of this article.

The authors' responsibilities were as follows: S. B. P. contributed to designing of the study, the data analysis and interpretation and wrote the manuscript. S. F. O. and colleagues initiated the Danish National Birth Cohort, and did the original dietary data collection. S. F. O. also contributed to the study design and interpretation. E. M., C. M. and P. V. contributed to study design, interpretation of the data and to the written manuscript. C. G. contributed with data analysis and 
management. M. S. supervised the study design, data analysis, interpretation and contributed to writing of the manuscript. All the authors had full access to study data.

None of the authors has any conflicts of interest.

\section{References}

1. Hernlund E, Svedbom A, Ivergard M, et al. (2013) Osteoporosis in the European Union: medical management, epidemiology and economic burden. A report prepared in collaboration with the International Osteoporosis Foundation (IOF) and the European Federation of Pharmaceutical Industry Associations (EFPIA). Arch Osteoporos 8, 136.

2. Heaney RP, Abrams S, Dawson-Hughes B, et al. (2000) Peak bone mass. Osteoporos Int 11, 985-1009.

3. Cooper C, Westlake S, Harvey N, et al. (2006) Review: developmental origins of osteoporotic fracture. Osteoporos Int 17, 337-347.

4. Cooper C (2005) Epidemiology of osteoporotic fracture: looking to the future. Rheumatology (Oxford) 44, iv36-iv40.

5. Javaid MK, Crozier SR, Harvey NC, et al. (2006) Maternal vitamin $\mathrm{D}$ status during pregnancy and childhood bone mass at age 9 years: a longitudinal study. Lancet 367, 36-43.

6. Ioannou C, Javaid MK, Mahon P, et al. (2012) The effect of maternal vitamin $\mathrm{D}$ concentration on fetal bone. J Clin Endocrinol Metab 97, E2070-E2077.

7. Sayers A \& Tobias JH (2009) Estimated maternal ultraviolet B exposure levels in pregnancy influence skeletal development of the child. I Clin Endocrinol Metab 94, 765-771.

8. Lawlor DA, Wills AK, Fraser A, et al. (2013) Association of maternal vitamin D status during pregnancy with bonemineral content in offspring: a prospective cohort study. Lancet 381, 2176-2183.

9. Zhu K, Whitehouse AJ, Hart P, et al. (2014) Maternal vitamin D status during pregnancy and bone mass in offspring at 20 years of age: a prospective cohort study. J Bone Miner Res 29, 1088-1095.

10. Lucas RM, Ponsonby AL, Pasco JA, et al. (2008) Future health implications of prenatal and early-life vitamin D status. Nutr Rev 66, 710-720.

11. Kimball S, Fuleihan G \& Vieth R (2008) Vitamin D: a growing perspective. Crit Rev Clin Lab Sci 45, 339-414.

12. Clark EM, Tobias JH \& Ness AR (2006) Association between bone density and fractures in children: a systematic review and meta-analysis. Pediatrics 117, e291-e297.

13. Ryan LM (2010) Forearm fractures in children and bone health. Curr Opin Endocrinol Diabetes Obes 17, 530-534.

14. Goulding A, Jones IE \& Taylor RW (2001) Bone mineral density and body composition in boys with distal forearm fractures: a dual-energy X-ray absorptiometry study. J Pediatr 139, 509-515.

15. Olsen J, Melbye M, Olsen SF, et al. (2001) The Danish National Birth Cohort - its background, structure and aim. Scand J Public Health 29, 300-307.

16. Olsen SF, Mikkelsen TB, Knudsen VK, et al. (2007) Data collected on maternal dietary exposures in the Danish National Birth Cohort. Paediatr Perinat Epidemiol 21, 76-86.

17. Jensen CB, Thorne-Lyman AL, Hansen LV, et al. (2013) Development and validation of a vitamin D status prediction model in Danish pregnant women: a study of the Danish National Birth Cohort. PLOS ONE 8, e53059

18. Nielsen NO, Strom M \& Boyd HA (2013) Vitamin D status during pregnancy and the risk of subsequent postpartum depression: a case-control study. PLOS ONE 8, e80686.
19. Ford L (2013) Measurement of vitamin D. Methods Mol Biol 1065, 245-257.

20. National Food Institute - Technical University of Denmark (2009) The Official Danish Food Composition Database. www.foodcomp.dk (accessed November 2013).

21. Willett WC, Howe GR \& Kushi LH (1997) Adjustment for total energy intake in epidemiologic studies. Am J Clin Nutr $\mathbf{6 5}$, 1220S-1228S.

22. Friis S, Kjaer SK, Stripp C, et al. (1997) Reproducibility and relative validity of a self-administered semiquantitative food frequency questionnaire applied to younger women. J Clin Epidemiol 50, 303-311.

23. Mikkelsen TB, Osler M \& Olsen SF (2006) Validity of protein, retinol, folic acid and $n-3$ fatty acid intakes estimated from the food-frequency questionnaire used in the Danish National Birth Cohort. Public Health Nutr 9, 771-778.

24. Mikkelsen TB, Olsen SF, Rasmussen SE, et al. (2007) Relative validity of fruit and vegetable intake estimated by the food frequency questionnaire used in the Danish National Birth Cohort. Scand J Public Health 35, 172-179.

25. Lynge E, Sandegaard JL \& Rebolj M (2011) The Danish National Patient Register. Scand J Public Health 39, 30-33.

26. Andersen TF, Madsen M, Jorgensen J, et al. (1999) The Danish National Hospital Register. A valuable source of data for modern health sciences. Dan Med Bull 46, 263-268.

27. Vestergaard P \& Mosekilde L (2002) Fracture risk in patients with celiac disease, Crohn's disease, and ulcerative colitis: a nationwide follow-up study of 16,416 patients in Denmark. Am J Epidemiol 156, 1-10.

28. Institute of Medicine (2011) Dietary Reference Ranges for Calcium and Vitamin D. Washington, DC: The National Academies Press.

29. National Board of Health (2010) Recommendations regarding prevention, diagnosis and treatment of vitamin D deficiency from the National Board of Health (Sundhedsstyrelsens anbefalinger vedrørende forebyggelse, diagnostik og behandling af D-vitaminmangel). Rationel Farmakoterapi jun 6 (in Danish). http://www.irf.dk/dk/publikationer/ratio nel_farmakoterapi/maanedsblad/2010/maanedsblad_nr_6_ juni_2010.htm (accessed October 2013).

30. Bertrand KA, Giovannucci E, Liu Y, et al. (2012) Determinants of plasma 25-hydroxyvitamin D and development of prediction models in three US cohorts. Br J Nutr 108, 1889-1896.

31. Guo S, Lucas RM \& Ponsonby AL (2013) A novel approach for prediction of vitamin D status using support vector regression. PLOS ONE 8, e79970.

32. Sohl E, Heymans MW, de Jongh RT, et al. (2014) Prediction of vitamin D deficiency by simple patient characteristics. Am J Clin Nutr 99, 1089-1095.

33. Tran B, Armstrong BK, McGeechan K, et al. (2013) Predicting vitamin D deficiency in older Australian adults. Clin Endocrinol (Oxf) 79, 631-640.

34. Jung S, Qian ZR, Yamauchi M, et al. (2014) Predicted 25(OH)D score and colorectal cancer risk according to vitamin D receptor expression. Cancer Epidemiol Biomarkers Prev 23, $1628-1637$

35. Joh HK, Giovannucci EL, Bertrand KA, et al. (2013) Predicted plasma 25-hydroxyvitamin D and risk of renal cell cancer. J Natl Cancer Inst 105, 726-732.

36. Jimenez M, Giovannucci E, Krall KE, et al. (2014) Predicted vitamin D status and incidence of tooth loss and periodontitis. Public Health Nutr 17, 844-852.

37. Ananthakrishnan AN, Khalili H, Higuchi LM, et al. (2012) Higher predicted vitamin D status is associated with reduced risk of Crohn's disease. Gastroenterology 142, 482-489. 
38. Conaway HH, Henning P \& Lerner UH (2013) Vitamin A metabolism, action, and role in skeletal homeostasis. Endocr Rev 34, 766-797.

39. Avenell A, Mak JC \& O'Connell D (2014) Vitamin D and vitamin $\mathrm{D}$ analogues for preventing fractures in post-menopausal women and older men. The Cochrane Database of Systematic Reviews, issue 4, CD000227.

40. Sanders KM, Stuart AL, Williamson EJ, et al. (2010) Annual high-dose oral vitamin $\mathrm{D}$ and falls and fractures in older women: a randomized controlled trial. JAMA 303, 1815-1822.

41. De-Regil LM, Palacios C, Ansary A, et al. (2012) Vitamin D supplementation for women during pregnancy. The Cochrane Database of Systematic Reviews, issue 2, CD008873.

42. Jensen CB, Petersen SB, Granström C, et al. (2012) Sources and determinants of vitamin $D$ intake in Danish pregnant women. Nutrients 4, 259-272.

43. Persson R, Garde AH, Hansen AM, et al. (2008) Seasonal variation in human salivary cortisol concentration. Chronobiol Int 25, 923-937.

44. Macdonald HM (2013) Contributions of sunlight and diet to vitamin D status. Calcif Tissue Int 92, 163-176.

45. Luykx JJ, Bakker SC, Lentjes E, et al. (2012) Season of sampling and season of birth influence serotonin metabolite levels in human cerebrospinal fluid. PLOS ONE 7, e30497.

46. Arendt J (1998) Melatonin and the pineal gland: influence on mammalian seasonal and circadian physiology. Rev Reprod 3, $13-22$.

47. Luboshitzky R, Yanai D, Shen-Orr Z, et al. (1998) Daily and seasonal variations in the concentration of melatonin in the human pineal gland. Brain Res Bull 47, 271-276.
48. Golan D, Staun-Ram E, Glass-Marmor L, et al. (2013) The influence of vitamin D supplementation on melatonin status in patients with multiple sclerosis. Brain Behav Immun 32, 180-185.

49. Tamura H, Nakamura Y, Terron MP, et al. (2008) Melatonin and pregnancy in the human. Reprod Toxicol 25, 291-303.

50. Anderson G (2010) Prenatal corticosteroids: pretermer outcomes, stress, schizophrenia, multiple sclerosis and the developmental role of melatonin and vitamin $\mathrm{D}_{3}$. J Pediatr Adolesc Gynecol 23, 317-320.

51. Bliziotes M (2010) Update in serotonin and bone. J Clin Endocrinol Metab 95, 4124-4132.

52. Hill TR, Aspray TJ \& Francis RM. (2013) Vitamin D and bone health outcomes in older age. Proc Nutr Soc 72, 372-380.

53. Lopez-Martinez F, Olivares Ponce PN, Guerra RM, et al. (2012) Melatonin: bone metabolism in oral cavity. Int J Dent 2012, 628406 .

54. Witt-Enderby PA, Slater JP, Johnson NA, et al. (2012) Effects on bone by the light/dark cycle and chronic treatment with melatonin and/or hormone replacement therapy in intact female mice. J Pineal Res 53, 374-384.

55. Zhou Y, Zhao LJ, Xu X, et al. (2014) DNA methylation levels of CYP2R1 and CYP24A1 predict vitamin D response variation. J Steroid Biochem Mol Biol 144, 207-214.

56. Gicquel C \& Wl-Osta Le BY (2008) Epigenetic regulation and fetal programming. Best Pract Res Clin Endocrinol Metab 22, $1-16$

57. Mathers JC \& McKay JA (2009) Epigenetics - potential contribution to fetal programming. Adv Exp Med Biol 646, $119-123$. 